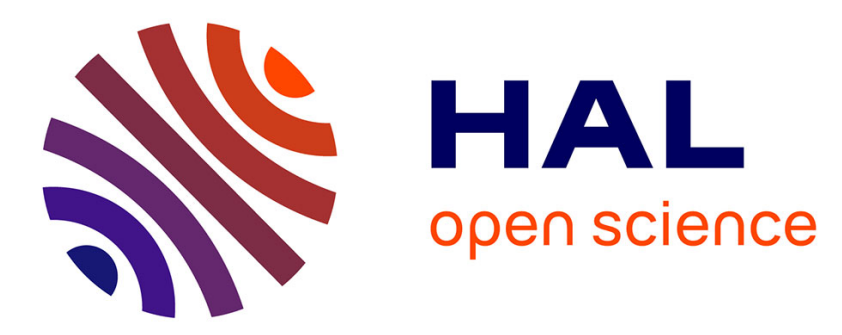

\title{
Nanotribology of nacre: Anisotropic dissipation in a multiscale hybrid material
}

Philippe Stempflé, Xavier Bourrat, Marthe Rousseau, Evelyne Lopez, Jamal Takadoum

\section{- To cite this version:}

Philippe Stempflé, Xavier Bourrat, Marthe Rousseau, Evelyne Lopez, Jamal Takadoum. Nanotribology of nacre: Anisotropic dissipation in a multiscale hybrid material. Tribology International, 2013, 63, pp.250-264. 10.1016/j.triboint.2012.09.010 . insu-00804509

\section{HAL Id: insu-00804509 https://hal-insu.archives-ouvertes.fr/insu-00804509}

Submitted on 2 Apr 2013

HAL is a multi-disciplinary open access archive for the deposit and dissemination of scientific research documents, whether they are published or not. The documents may come from teaching and research institutions in France or abroad, or from public or private research centers.
L'archive ouverte pluridisciplinaire HAL, est destinée au dépôt et à la diffusion de documents scientifiques de niveau recherche, publiés ou non, émanant des établissements d'enseignement et de recherche français ou étrangers, des laboratoires publics ou privés. 


\title{
Nanotribology of nacre : anisotropic dissipation in a multiscale hybrid material
}

\author{
Philippe Stempflé ${ }^{a)}$, Xavier Bourrat $^{b)}$, Marthe Rousseau $^{c)}$, Evelyne Lopez $^{d)}$, Jamal Takadoum ${ }^{a}$ ) \\ a) Institut FEMTO-ST (UMR CNRS 6174 - Universite de Franche Comte - CNRS - ENSMM - UTBM), ENSMM 26 \\ Chemin de l'Epitaphe, F-25030 Besancon Cedex, FRANCE \\ b) Orleans University CNRS ISTO, 1 A Rue de Ferollerie, 45071 Orleans Cedex 2, FRANCE \\ c) Nancy University (UMR CNRS 7561), 9 Avenue de la Foret de Haye, 54505 Vandoeuvre les Nancy, FRANCE \\ d) Museum National d'Histoire Naturelle (UMR 5178 CNRS-MNHN), CP 51, 55 Rue Buffon, 75005 Paris, FRANCE
}

\begin{abstract}
Sheet nacre (so called mother-of-pearl) is a hybrid biocomposite with a multiscale structure including nanograins of calcium carbonate (97 wt.\% - $40 \mathrm{~nm}$ in size) and two organic matrices: (i) the "intracrystalline" (mainly composed by silk-fibroin-like proteins), and (ii) the "interlaminar" one (mainly composed of $\beta$-chitin and proteins). Micro/Nanotribological behaviour was investigated on sheet nacre displaying various configurations (so-called face-on and edge-on), by varying the orientation of the matrices vs. the sliding direction. Different levels of frictional dissipated energy were observed as a function of both: (i) the type of matrix which is involved in the dissipation mechanism (intracrystalline or interlaminar), and (ii) the orientation of the matrices themselves vs. the sliding direction. These various dissipative ways can involve either, multiscale wear processes entailing the both matrices, or irreversible deformation only, without any wear process. They have been identified and explained by considering the double composite structure of sheet nacre.
\end{abstract}

Keywords: mother of pearl, biocrystal, modulus, strength, organic matrix, in situ wear assessment, tribolayer

\section{Introduction}

Sheet nacre (the pearly internal layer of molluscan shells) is a hybrid biocomposite with a multiscale structure including nanograins of calcium carbonate (97 wt.\%) $[1,2,3]$ and two organic matrices (3 wt.\%) $[3,4,5]$. At the nanoscale, biocrystals (ca $40 \mathrm{~nm}$ in size) are drowned in an "intracrystalline" organic matrix (4 nm thick) in order to form a microsized flat organomineral aragonite tablet (thickness about $500 \mathrm{~nm})[6,7,8,9]$. At a larger scale $[10,11,12,13,14]$, these tablets are themselves surrounded by a porous "interlaminar" organic matrix (thickness: $40 \mathrm{~nm}$, porosity in-between $35 \%$ and $59 \%$ ) building up a

Email address: philippe.stempfle@ens2m.fr (Philippe Stempflé $\left.{ }^{a}\right)$, Xavier Bourrat ${ }^{b}$, Marthe Rousseau ${ }^{c}$, Evelyne Lopez $^{d)}$, Jamal Takadoum ${ }^{a)}$ ) 
material displaying highly interesting properties [15, 16, 17, 18, 19, 20, 21]: low density, good biocompatibility $[22,23,24,25]$ and osteogenic properties for human bone regeneration [22, 26, 27, 28]. Thus, this material is currently being studied as small prostheses (eg, rachis and dorsal vertebra prostheses, which are both subjected to microslip and fretting wear), or for the creation of new organic/inorganic bio-inspired hybrid materials $[29,30,31,32,33,34,35]$.

Recently, friction and wear behaviour of sheet nacre were studied in dry friction [36, 37, 38, 39] and in liquid medium [36], respectively. Results have shown that:

- (i) the environment strongly influences the wear mechanisms of nacre by means of various physicochemical interactions on the water-soluble "intracrystalline" organic phase [36];

- (ii) the energy absorption ability of the matrix is drastically reduced in presence of nanoshocks generated during friction by the dynamic solicitations. As a result, cracks migrate in the tablet involving the formation of wear nano-debris [37];

- (iii) at high mean contact pressure, additional thermal-induced wear damage involves the degradation of the organic matrices, that increases dramatically the wear rate of nacre [38, 39, 40];

Thus, for this kind of solicitations, nacre is clearly subjected to peculiar thermal $[38,41]$ and mechanical $[36,37]$ damage processes, which occur at two order of magnitude, involving its double composite structure i.e both organic matrices are always directly involved in the friction-induced energy dissipation mechanisms $[42,43,44,45,46,47,48]$ and in the subsequent damage mechanisms, as well $[42,49,50,51,52,53]$. So, the orientation of the tablets $[14,54]$ - and especially the one of the matrices themselves - with respect to the sliding direction seems to be a key parameter for understanding the dissipation mechanisms of sheet nacre under dynamic solicitations, as met in tribological tests. Indeed, anisotropic specificities of sheet nacre under quasi-static solicitations - (i.e, tension [15, 49, 55, 56], three- and four-point bending [44], shear [44, 57], micro- $[56,57,58,59]$ and nano-indentation $[37,53,60,61,62,63])$ have been actively studied or modelled $[45,54]$ in the past. But, up to now, tribological results have been achieved with a face-on configuration sheet nacre only $[36,37,38,39]$ - i.e, when the tablets are oriented more or less parallel to the friction direction -, leaving the study of the real influence of the tablets orientation on the wear mechanisms not investigated yet.

This work aims to compare friction and wear mechanisms of sheet nacre cut with a face-on and a edge-on configuration, respectively, in order to understand how the orientations of the organic phases $v s$. the sliding direction can change the ways to dissipate the frictional energy. In order to avoid any additional thermal effects, and to better control the environment around the contact, tribological tests have been carried out 
under low contact pressures, by using a multi-asperity nanotribometer $[64,65,66]$ working in an environmental glove box .

\section{Experimental part}

\subsection{Samples}

Samples are made of dry sheet nacre extracted from giant oyster Pinctada maxima $[3,4,6,7,8,36,67]$ cut with a face-on and edge-on configuration, respectively (fig 1). Surfaces are polished with a RMS roughness about $14.5 \pm 0.6 \mathrm{~nm}$. Three configurations have been tested with respect to the direction of sliding:

- a face-on configuration parallel to the direction of sliding (fig 1a);

- an edge-on configuration perpendicular to the direction of sliding (fig 1b);

- an edge-on configuration parallel to the direction of sliding (fig 1c);

As mentioned previously, this type of sheet nacre has a multiscale structure [3, 68, 69]:

- On the one hand, aragonite tablet (500 to $700 \mathrm{~nm}$ thick) are surrounded by an "interlaminar" thin network (about $40 \mathrm{~nm}$ thick) of a biological porous organic adhesive (average porosity $49 \pm 12 \%$ [63]) mainly composed of $\beta$-chitin and proteins $[10,11,12,13]$.

- On the other hand, each aragonite tablet is constituted by nanosized biocrystals of $\mathrm{CaCO}_{3}$ surrounded by a water-soluble "intracrystalline" organic phase (mainly silk-fibroin-like proteins) organised as a foam with very thin walls and closed porosity $(4 \mathrm{~nm})[3,4,6,7,8,36]$. The average size of these initial biocrystals is about $38 \pm 21 \mathrm{~nm}$ [62].

In addition, mechanical properties of each component - i.e biocrystals and organic matrices - have previously been assessed by using SEM analysis, acoustic microscopy [63, 70], spherical and sharp nanoindentation tests [37, 60, 62], combined with multiscale numerical simulations using FEM [37, 39] and homogenization approach [62]. Main mechanical features are reported in table 1. The mechanical properties of the "interlamellar" matrix are very close to the ones determined by Xu et al using more local assessments [71].

\subsection{Nanotribological setup}

\subsection{1. in situ friction assessment}

The experimental device (fig 2a) is constituted by a ball-on-disc nanotribometer manufactured by CSM Instruments (Switzerland) [66,72]. A pin is mounted on a stiff lever, designed as a frictionless force transducer

$\left(K_{x}=265.1 \mathrm{Nm}^{-1} ; K_{z}=152.2 \mathrm{Nm}^{-1}\right)$. The friction force is determined during the test by measuring the deflection of the elastic arm (low load range down to $50 \mu \mathrm{N})$. The ball $\left(S i_{3} N_{4}-\varnothing 1.5 \mathrm{~mm}\right.$ ) is loaded onto a flat nacre sample with a precisely known force using closed loop. The load and friction resolutions are 
about $1 \mu \mathrm{N}$. Tribological tests are carried out in linear reciprocating mode at room temperature $\left(22^{\circ} \mathrm{C}\right)$

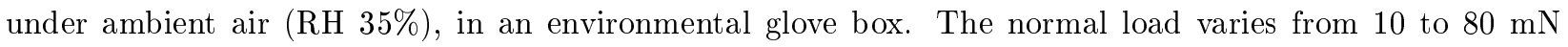
corresponding to a contact pressure varying from 0.15-0.65 GPa. The stroke frequency, the stroke length and the stroke length resolution are respectively $10 \mathrm{~Hz}, \pm 0.5 \mathrm{~mm}$, and $250 \mathrm{~nm}$. The velocity and the sliding distance are respectively $1 \mathrm{~mm} . \mathrm{s}^{-1}$ and $0.2 \mathrm{~m}$, corresponding to 100 cycles in order to reach the steady state in friction.

Due to the level of the frictional energy really dissipated within the contact (few $\mu \mathrm{J} /$ cycle), the thermal contribution is greatly limited and clearly too low for melting the matrices [38, 39, 40, 41]. The energy dissipated per cycle is computed as the work of the tangential force versus displacement loops recorded on-line (fig 2b). In order to notice any effect of the nacre microarchitecture orientation on the tribological behaviour, difference between the "forward" and "backward" friction is assessed by studying any asymmetry along the $y$-axis of the friction loops with respect to ordinate origin (fig $2 \mathrm{~b}$ ). This difference is then compared to the standard deviation of the friction coefficient, extracted from the friction loop.

\subsection{2. in situ wear assessment}

As shown in the fig $2 \mathrm{a}$, a real-time depth measuring optical sensor is used for studying any time-dependent wear process [66, 72]. Its depth range varies from $20 \mathrm{~nm}$ to $100 \mu \mathrm{m}$ with a resolution of about $20 \mathrm{~nm}$. Results is compiled as a triboscopic approach [72] giving simultaneously, and for each cycle:

- (i) the friction map (fig 3a), plotting the evolution of the friction coefficient along the friction track ;

- (ii) the wear map (fig 3b) which reveals any time-dependent wear process and/or potential build-up of a tribolayer within the contact. This map is computed from an in situ depth map by taking into account the tilting and the initial deformation of the samples, respectively [72, 73]. Finally, an in situ wear rate assessment can be directly extracted from this wear map (fig $3 \mathrm{~b}$ ) as a classical profile analysis (fig 3c), by using a topographical software (eg. Gwyddion).

\subsection{Atomic force microscopy}

Topography of the friction tracks and elemental wear mechanisms are assessed using an AFM Dimension 3000 connected to a Nanoscope IIIa electronic controller (Digital Instruments Santa Barbara, USA). Its spatial and vertical resolutions are lower than $1 \mathrm{~nm}$ and the field depth is in-between $100 \mathrm{~nm}$ and 100 um. Maps were achieved at high resolution $\left(512 \times 512\right.$ pixels) using an intermittent contact mode (TappingMode $\left.{ }^{T M}\right)$ and a Phase Detection Imaging. The silicon nitride probe displays a tip rounding lower than $10 \mathrm{~nm}$. The work frequency, the stiffness and the cantilever amplitude are respectively: $270 \mathrm{kHZ}, 42 \mathrm{Nm}^{-1}$, and $25 \mathrm{~nm}$. According to the size of the images (between $0.25 \mu^{2}$ and $25 \mu^{2}$ ) the scanning rates varies from $1 \mu \mathrm{ms}^{-1}$ to 


\begin{tabular}{cccc}
\hline & $\mathrm{E}(\mathrm{GPa}$ & $\nu$ & $\sigma_{y}(\mathrm{GPa})$ \\
\hline Aragonite biocrystals & $96.75(5.67)^{\mathrm{a}}$ & $0.17(0.05)^{d}$ & $13.4(2.1)^{\mathrm{b}}$ \\
$50 \%$ porous "interlaminar" organic matrix & $13.4(0.79)^{\mathrm{c}}$ & $0.29(1.7 \mathrm{e}-3)$ & $0.118(0.02)$ \\
"intracrystalline" organic matrix & $3.81(0.41)^{d}$ & $0.296(1.4 \mathrm{e}-3)^{\mathrm{d}}$ & - \\
\hline
\end{tabular}

a) assessed by sharp nanoindentation test [62]

b) computed by a Hertzian model [62]

c) assessed by combining acoustic microscopy and spherical nanoindentation test [63]

d) computed by a Mori-Tanaka model [62]

Table 1: Mechanical properties of elemental components of dry sheet nacre

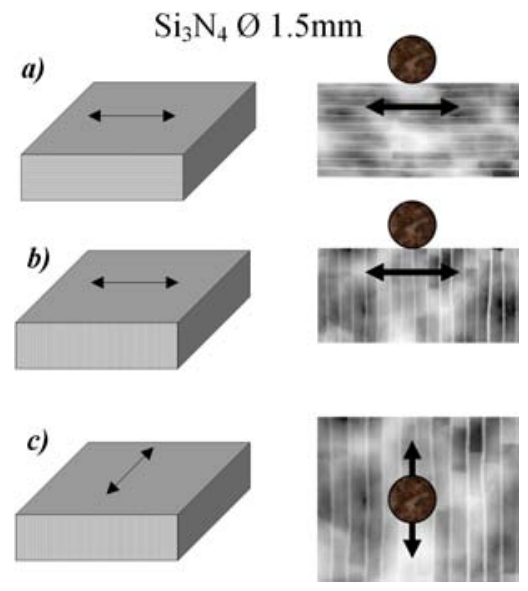

Figure 1: Various configurations of the samples: (a) face-on orientation ; (b) edge-on perpendicular to the sliding direction, and (c) edge-on parallel to the sliding direction
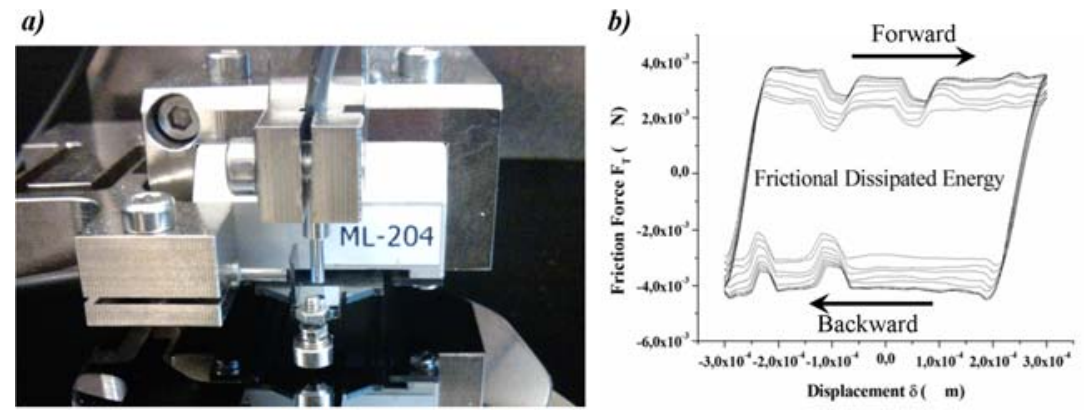

Figure 2: Nanotribological setup: (a) picture showing the two real-time measuring optical sensors (i) the horizontal one records the friction force and (ii) the vertical one records the time-dependent wear properties; (b) typical view of the friction loop allowing to compute the dissipated frictional energy, and the difference between the forward and backward friction force 

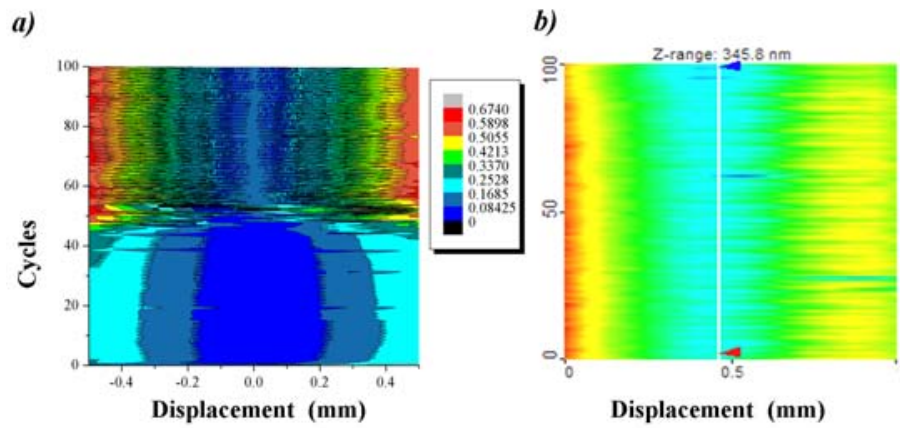

c)

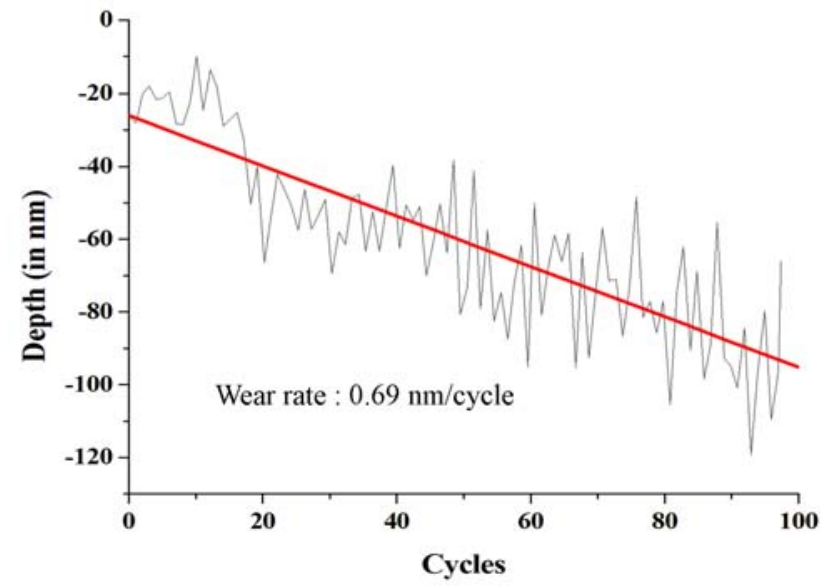

Figure 3: Typical views resulting from the in situ triboscopic approach giving simultaneously and for each cycle: (a) the evolution of the friction coefficient along the friction track (friction map); (b) the evolution of the time-dependent wear process and/or potential build-up of a tribolayer within the contact (wear map); and (c) the in situ wear rate assessment by using a classical profile analysis 
$2.4 \mathrm{\mu ms}^{-1}$. The size of the wear debris and the initial biocrystal nanograins respectively, were determined from the phase contrast maps with a specific algorithm developed for the SPM data analysis software Gwyddion (http://gwyddion.net).

\section{Results and discussion}

\subsection{Nanotribological results in the face-on configuration parallel to the direction of sliding}

As shown in the fig $4 \mathrm{a}$ and $\mathrm{b}$, there are two different frictional regimes for the same range of normal loads $(10$ to $80 \mathrm{mN})$, :

- (i) a high level regime (fig 4a) displaying a high level coefficient of friction, which is very close to the one observed in our previous macrotribology experiments [36, 37]. As expected (fig 5), these high friction values are connected to a high wear rate $\left(20\right.$ nm.cycle $\left.{ }^{-1} \cdot N^{-1}\right)$. Wear (fig 5a) was computed by integrating the height distribution histograms (fig $5 \mathrm{~b}$ ) assessed, for each normal load, by using a phase-shifting interferometric profilometer on the inverted friction scars (fig 5c) [74].

- (ii) a low level regime (fig $4 \mathrm{~b}$ ) which is, in contrast, specific to the micro/nanotribology experiments, and never observed before.

However, whatever the frictional regime, a load bearing capacity is clearly developed by increasing the normal load (fig 4a and b): the higher the normal load, the lower the coefficient of friction. So, an in situ approach is needed for explaining what is happening within the contact.

\subsection{1. in situ tribological behaviour in the face-on high level regime}

Fig 6 displays the in situ tribological behaviour in the face-on high level regime, for two typical normal loads (20 mN and $70 \mathrm{mN}$ ), respectively. Whatever the normal loads, the friction maps (fig 6a and b) are very unstable along the friction track and with time, because a heterogeneous tribolayer is continuously built-up and removed within the contact, as shown in the wear maps (fig 6c and d).

In order to estimate the amount of wear debris trapped within the contact, the tribolayers' thickness is computed, in both cases, from the profile analyses (fig 6e) carried out on the respective wear maps (fig 6c and d). After a first deformation due to the initial contact (fig 6e), a gradual build-up of the tribolayer is clearly observed, starting after the ten first cycles. Its thickness evolves with the number of cycles but, it increases with the normal load and even overshoots several micrometers for the highest normal load. Thus, this thickness is always higher than a single tablet's thickness (about $500 \mathrm{~nm}$ ), revealing that several layers of tablets are probably involved in the wear process. Besides, successive jumps and drops observed on the wear profile (fig 6e) are always in the same order of magnitude as the tablets' thickness, suggesting some tablets' movement under the slider: hence, pieces of tablets are directly involved by the wear mechanism. As 
a)

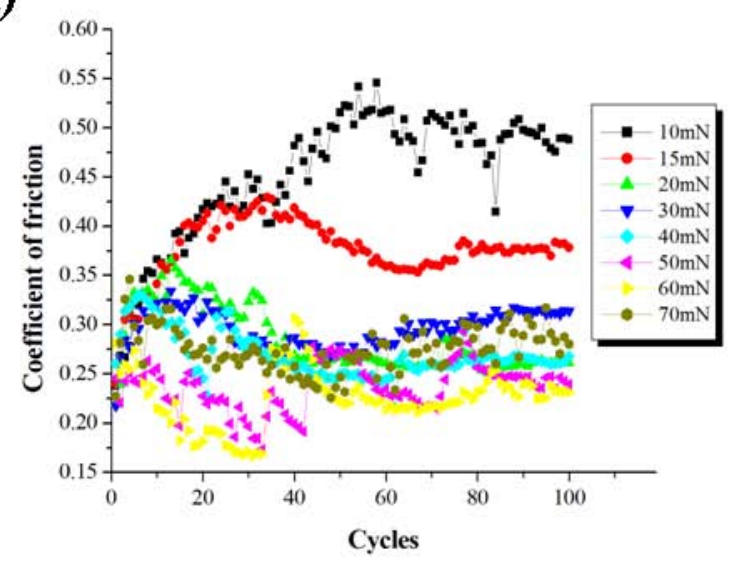

b)

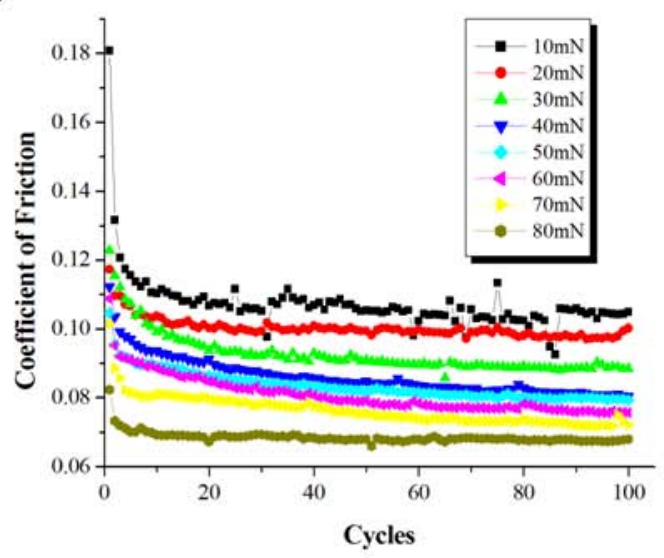

Figure 4: Evolution of the coefficient of friction with the normal load in the face-on configuration: (a) high level regime, and (b) low level regime
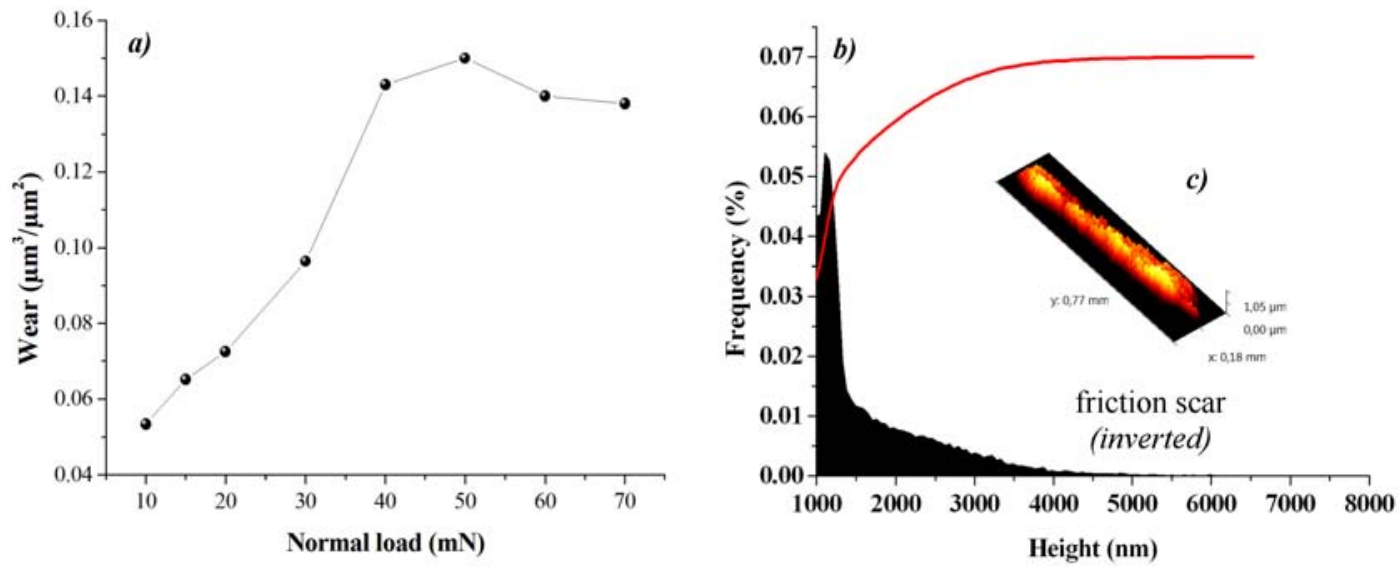

Figure 5: Wear assessment in the face-on high level regime: for each applied normal load, wear (a) is computed by integration of the height distribution histograms (b) from the topographical features of the inverted friction scar (c) 
a result, the amount of the wear debris trapped within the contact is very important and so, the size of the wear debris itself, as reported in the typical SEM views after sliding (fig 7).

- For the lowest load (fig 7a), the contact occurs mainly on the first bodies. The size of the huge debris clearly involves the cracking of tablets and so, the fracturing of the "interlaminar" organic matrix as a main wear mechanism.

- For the highest normal load (fig $7 \mathrm{~b}$ and $\mathrm{c}$ ), the tribolayer appears more continuous due to a much more important amount of debris. In addition to the initial tablets' fracturing, the wear behaviour involves the crushing of the initial huge debris (fig $7 \mathrm{~b}$ ). Hence, their progressive compaction as a continuous tribolayer (fig $7 \mathrm{c}$ ) is probably connected to the development of the mentioned load bearing capacity, as observed in fig 4a. This process can be attributed to the nanograined-structure of the hybrid biocrystal which does not undergo brittle fracture, but ductile deformation at this scale.

As expected, the main wear mechanism in high level regime is then similar to the one reported in macrotribological tests carried out with face-on sheet nacre samples [36]: (i) the initial fracture of the "interlaminar" organic matrix, (ii) the crumbling of the aragonite tablets and finally, (iii) the agglomeration and compaction of the crumbled particles within the contact. Besides, the load bearing capacity effect observed as a function of the normal load seems only connected to the amount of compacted ductile debris trapped within the contact, which act on the frictional behaviour as a negative feedback loop [75]. In addition, no effect due to the nacre microarchitecture orientation has been observed in this regime: the frictional behaviour is completely controlled by the thick tribolayer. So, what is the difference with the low level regime?

\subsection{2. in situ tribological behaviour in the face-on low level regime}

In contrast to the previous regime, the low level regime has never been observed in macrotribological tests. As shown in fig 8a for the same range of normal loads, the level of the dissipated frictional energy is only the quarter of the one observed in the high level regime. Nevertheless, this behaviour is connected with a significant wear process, as shown on the typical SEM views observed after sliding (fig 8b and c). It is worth of noting that this difference of dissipated energy is similar to the ratio between the strengths of the organic matrices (table 1). So, a change of wear mechanism - which would involve the fracturing of "intracrystalline" instead of "interlaminar" organic matrix - is probably expected.

To check this assumption, in situ tribological behaviour is reported in fig 9 , for two normal loads (20 mN and $70 \mathrm{mN}$ ). In contrast to what is observed in high level regime (fig 6), friction maps are very smooth along the friction track and with time, whatever the normal load (fig 9a and b). Similarly, wear maps are also quite homogeneous and reveal that cohesive tribolayers are continuously built-up during the test (fig 9c and d). They are never removed during the tests, in contrast to what is observed for the high level regime (fig 


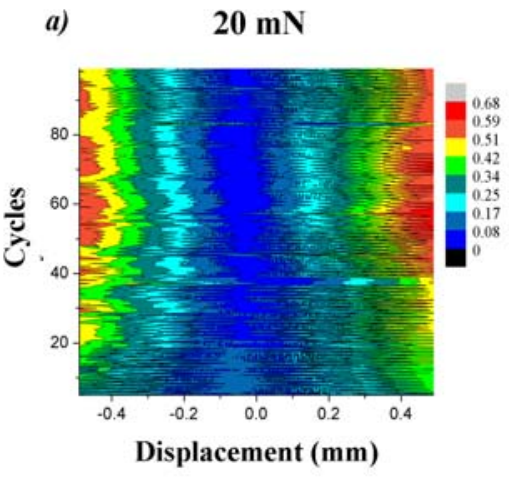

c)

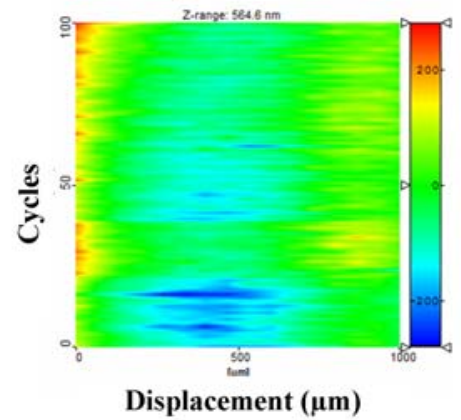

b)

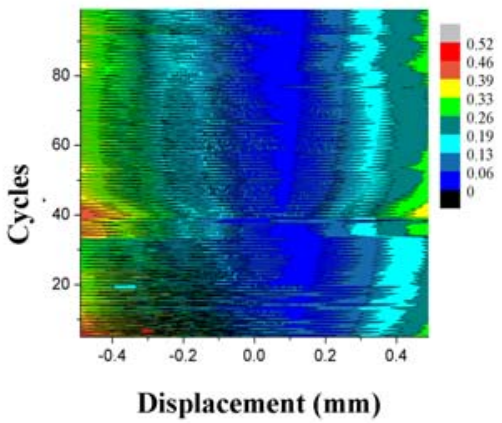

d)

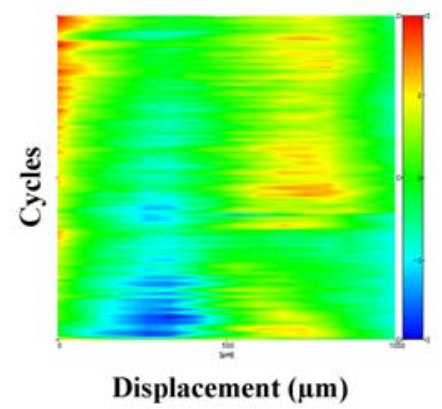

e)

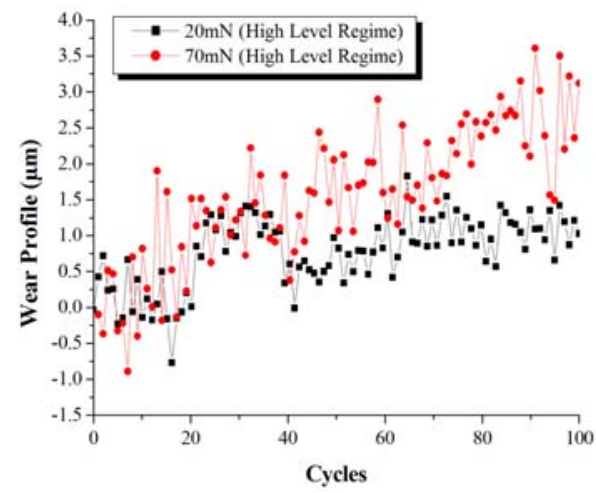

Figure 6: in situ tribological behaviour in the face-on high level regime for two applied normal loads: (a) friction maps at 20 $\mathrm{mN}$, and (b) at $70 \mathrm{mN}$; (c) wear maps at $20 \mathrm{mN}$, and (d) at $70 \mathrm{mN}$; (e) corresponding in situ wear profile assessment carried out in the center of the friction track
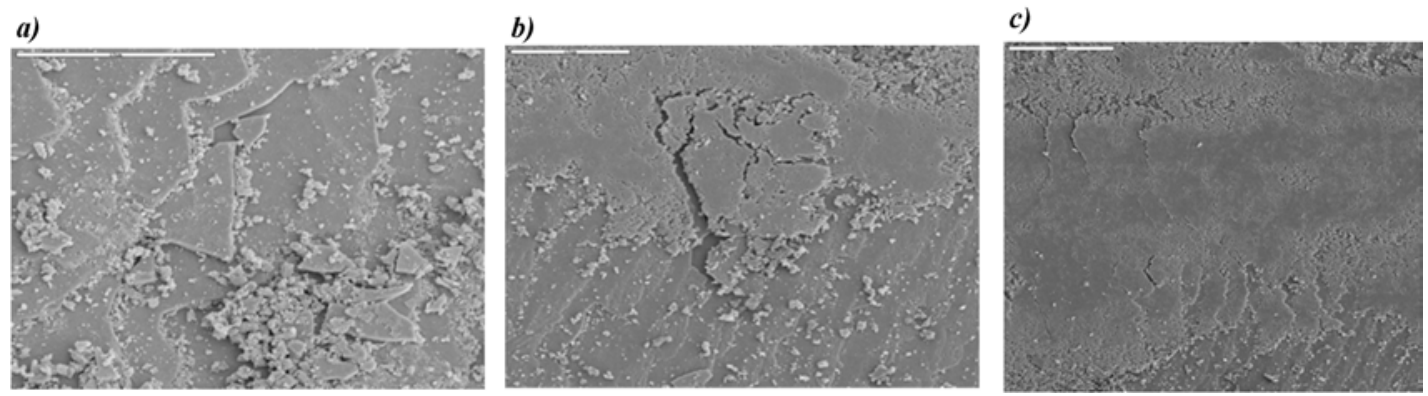

Figure 7: Typical SEM views of the friction track in the face-on high level regime: (a) at low applied normal load (20 mN - bar is $10 \mu \mathrm{m})$;(b and c) at high applied normal load (70 $\mathrm{mN}-$ bar is $10 \mu \mathrm{m}$ and $20 \mu \mathrm{m}$, respectively) 
a)

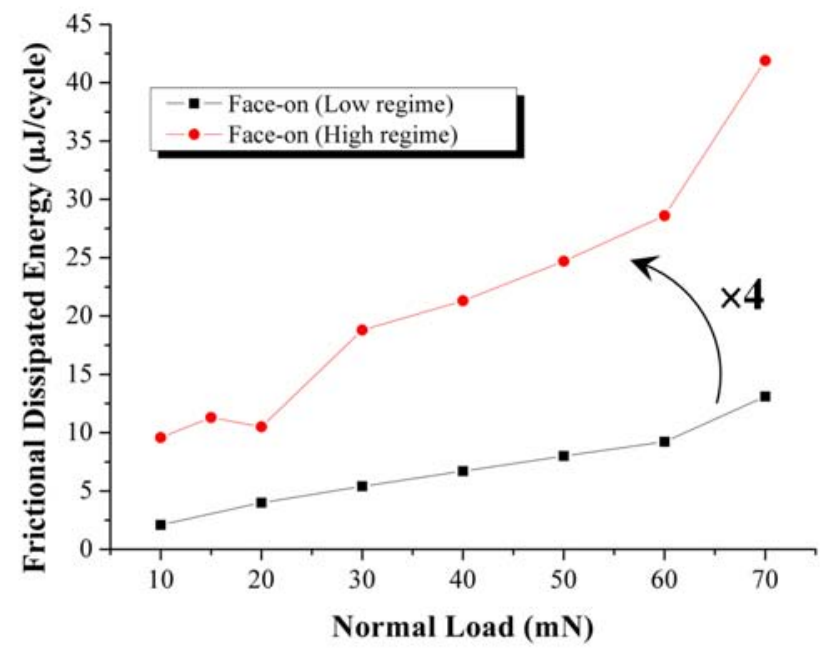

b)

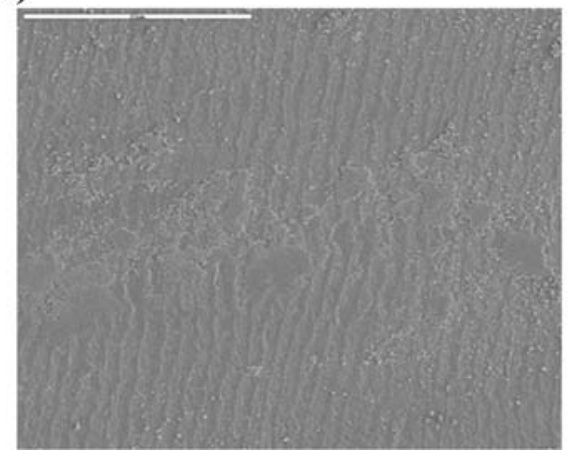

c)

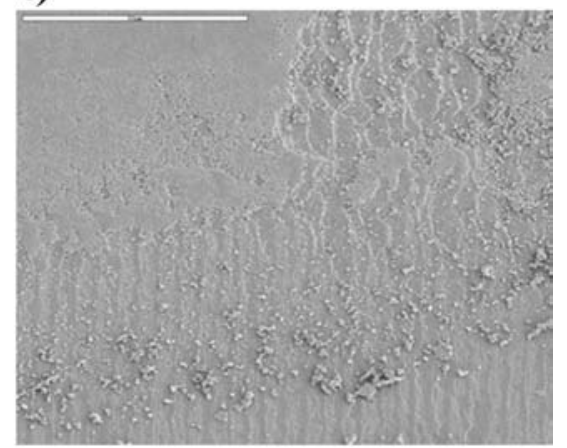

Figure 8: Tribological features in the face-on low level regime: (a) evolution of the dissipated energy with the applied normal load vs. that of high regime; (b) and (c) typical SEM views of the friction track at low (20 mN) and high normal load (70 mN), respectively (bars are $50 \mu \mathrm{m}$ ) 
6). The cohesion ability of tribolayers being generally linked to the size of the elemental wear debris which constitute them [75], AFM image analysis (fig 9e) confirms that this size is very close to the one of the initial biocrystals.

Wear profiles (fig 10a) extracted from wear maps (9c and d) also confirm the presence of a very thin tribolayers whose thicknesses are never over the initial tablet's thickness (above $500 \mathrm{~nm}$ ). That means that only one layer of tablets is here involved in the wear process. This result is also observed on typical SEM views (fig 10b).

Thus, in face-on low level regime, the wear mechanism would be mainly a fracturing within the tablet involving the "intracrystalline" organic matrix only. That would explain the reduction of the frictional dissipated energy mentioned above (fig 8a). Besides, this wear mechanism is clearly observed after sliding, on typical SEM (fig 10c) and AFM views (fig 10d), which both reveal the crumbling of the tablets instead of a clear cutting (fig 7a). This observation is also in good agreement with the distribution of wear debris' size (fig 9e). So, the main wear mechanism is due here to a detachment of initial biocrystals from the top row of tablets by breaking of the "intracrystalline" organic matrix. However, why are there two frictional levels in this face-on configuration?

\subsubsection{Transition from low to high level regime}

Typical profilometrical view of the friction track after the sliding test (fig 11a) reveals that the high level regime is always observed when the friction track has passed through an initial scratch, deeper than the tablets' thickness. In order to check this assumption, tribological behaviour of initially scratched surfaces is compared to the one of virgin surfaces (fig 11b). As expected, whatever the normal load, the coefficient of friction strongly increases and stays at the high level in presence of an initial scratch. Thus, in face-on configuration, friction and wear appear very sensitive to the track smoothness, as shown in fig 11c. As long the scratches are still below the critical depth, i.e, close to the tablets' thickness, fracturing occurs within the tablets involving the "intracrystalline" matrix only. But as soon as the scratch's thickness overshoots the critical size (here around 35 cycles), the fracturing location moves from the "intracrystalline" matrix to the "interlaminar" one. As a result, the frictional dissipation energy suddenly increases because the two matrices are involved, but, at that time, the influence of the "intracrystalline" matrix is almost imperceptible, completely hidden by the "interlaminar" one.

As expected, the influence of nacre microarchitecture controls the tribological behaviour in low level regime, only. Because in high level regime, the formation of a tribolayer is sufficient for controlling the frictional and wear behaviour in the place of the initial nacre structure. So, what is now the effect of an orientation change on the tribological behaviour? 


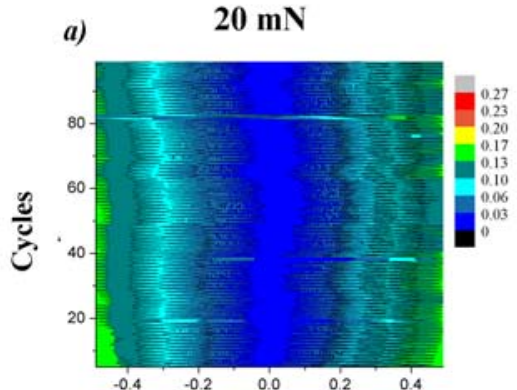

Displacement (mm)

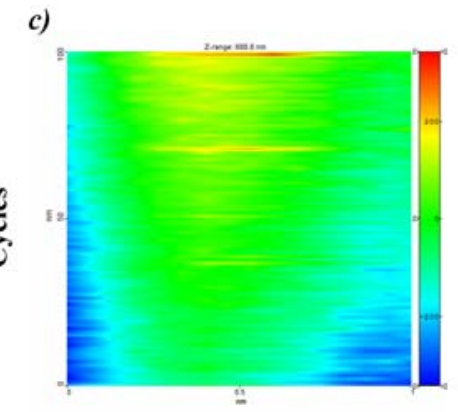

Displacement (mm)
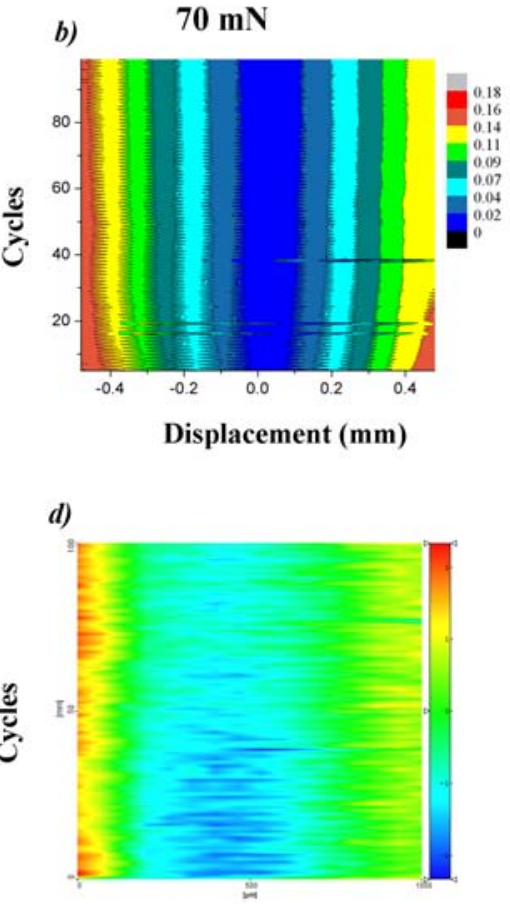

Displacement $(\mu \mathrm{m})$

\section{e)}

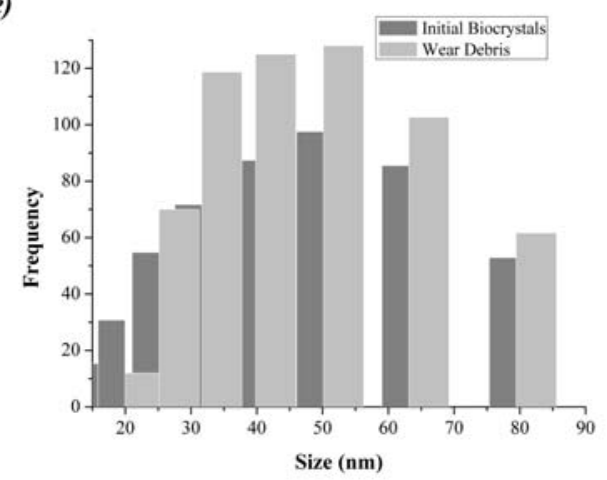

Figure 9: in situ tribological behaviour in the face-on low level regime, for two applied normal loads: (a) friction maps at 20 $\mathrm{mN}$, and (b) at $70 \mathrm{mN}$; (c) wear maps at $20 \mathrm{mN}$, and (d) at $70 \mathrm{mN}$. (e) Comparison of the particles size distribution curves of wear debris with that of nanograins in the initial biocrystal 
a)

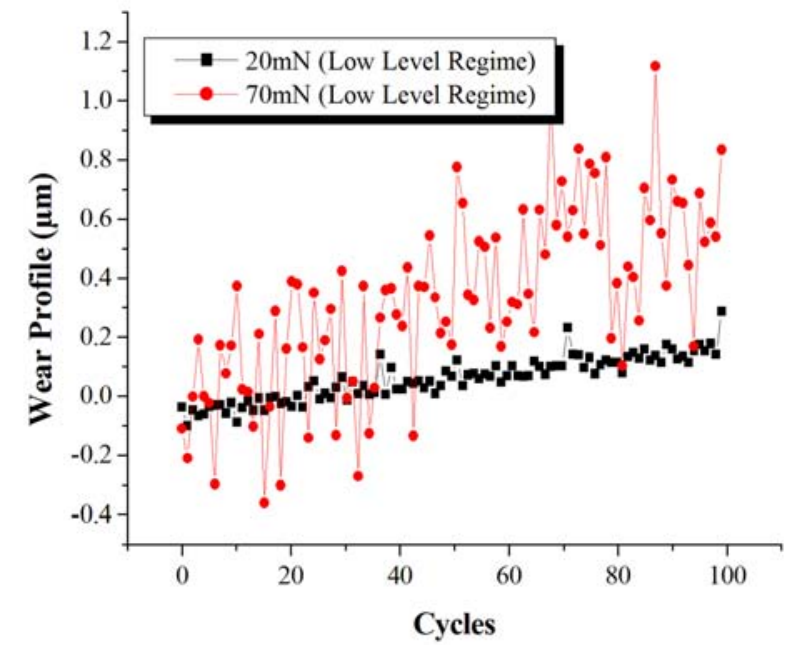

b)

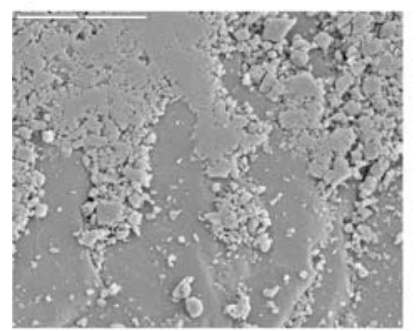

c)

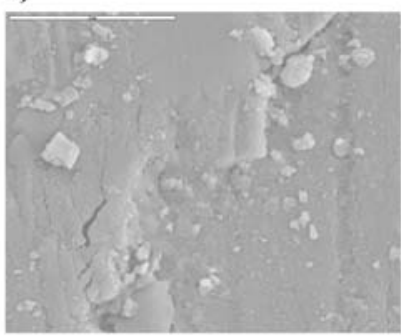

d)

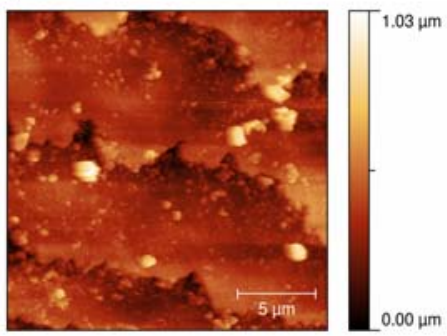

Figure 10: Wear features in the face-on low level regime: (a) in situ wear profile assessment carried out in the center of the friction track; (b) typical SEM view of the friction track; (c) and (d) typical views of the wear mechanism occuring the in face-on low level regime in SEM and AFM, respectively (bar is $5 \mu \mathrm{m}, 2 \mu \mathrm{m}$ and $5 \mu \mathrm{m}$, respectively) 


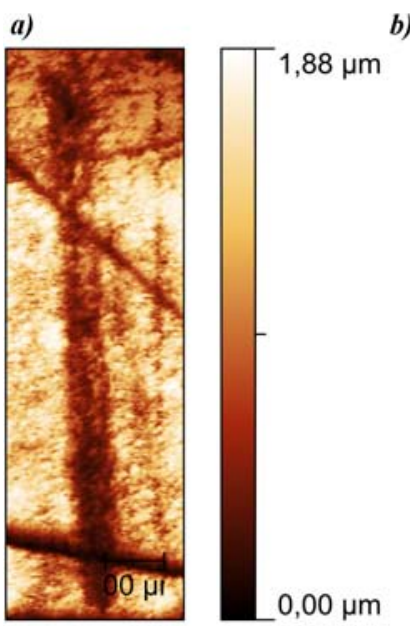

b)

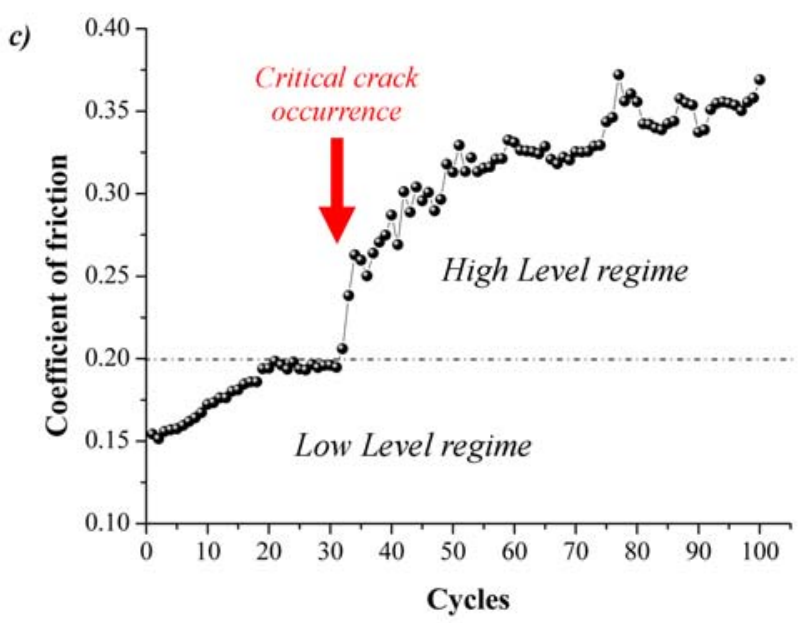

Figure 11: (a) Typical view of the friction track after sliding in the face-on high level regime ; (b) Evolution of the friction coefficient in absence and in presence of scratch;(c) example of transition from low to high level friction regime due to the occurence of a critical crack around 35 cycles (Normal load $30 \mathrm{mN}$ ): 
3.2. Nanotribological results in the edge-on configuration perpendicular to the direction of sliding

3.2.1. Variation of the friction coefficient: virgin polished surface vs. polished surface with scratches

The experiments are conducted now with the tablets edge-on and perpendicular to the sliding direction.

Fig $12 \mathrm{a}$ and $\mathrm{b}$ show the evolution of the coefficient of friction vs. number of cycles for various normal loads, in absence (fig 12a) and in presence of an initial scratch (fig 12b), respectively.

- In absence of scratch (fig 12a), the frictional behaviour is similar to the one observed in the previous face-on low level regime. A load bearing capacity effect is also observed as a function of the normal load revealing a possible feedback effect of a tribolayer on the friction coefficient behaviour. As expected for low level regime, there is no effect of the initial microarchitecture orientation: "forward" and "backward" friction coefficient are quite similar $(i . e$ the difference stays lower than the friction coefficient's standard deviation).

- As expected too, the coefficient of friction strongly increases and stays at a high level regime in presence of an initial scratch (fig 12b).

Thus, similarly to the previous face-on configuration, there are two antagonistic friction regimes, which are sensitive to the presence of critical cracks or scratches. But, in contrast the wear behaviour appears very different because it does not change with the friction regimes - i.e, in absence or in presence of an initial scratch.

\subsection{2. in situ tribological behaviour}

Indeed, in contrast to what is observed in face-on configuration, only few debris are observed within the friction track (fig 13a): the coarse ones come from the initial scratch and are not agglomerated together, so they are quickly ejected on the friction track edges and beyond the ends. Besides, an enlargement on the friction track (fig 13b and c) reveals that a very thin and discontinuous tribolayer is observed even so. Its thickness is computed by triboscopic analyses (fig 14), respectively in absence (fig 14b), and in presence (fig 14c) of the initial scratch, for two typical normal loads (30 and $50 \mathrm{mN})$.

After an initial deformation, a tribolayer is gradually built-up with time (fig 14a). It appears very heterogeneous along the friction track, whatever the applied normal load (fig 14b). The amount of debris is quite low, even in presence of an initial scratch (fig 14a and c): thus,

- in absence of scratch (i.e in low level regime), the tribolayer's thickness (fig 14a) is in the same order of magnitude as the size of the nanograins $(50 \mathrm{~nm})$;

- and is lower than ten layers of biocrystals in presence of initials scratches (i.e in high level regime). 
a)

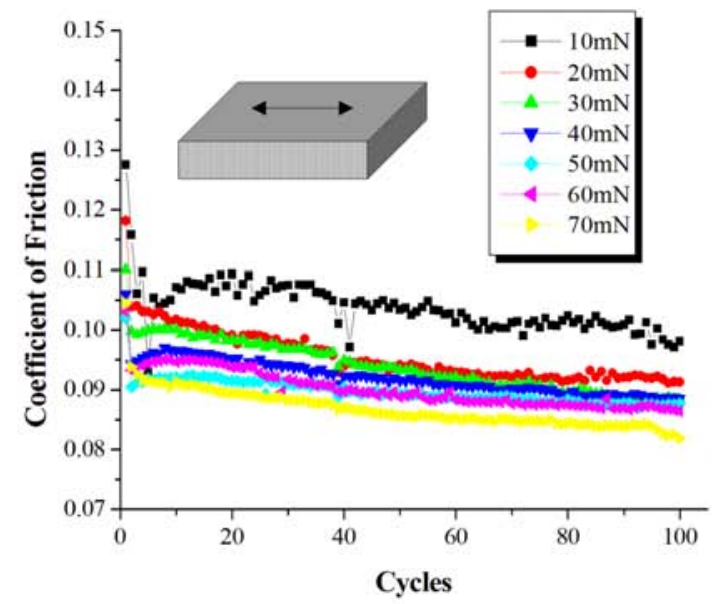

b)

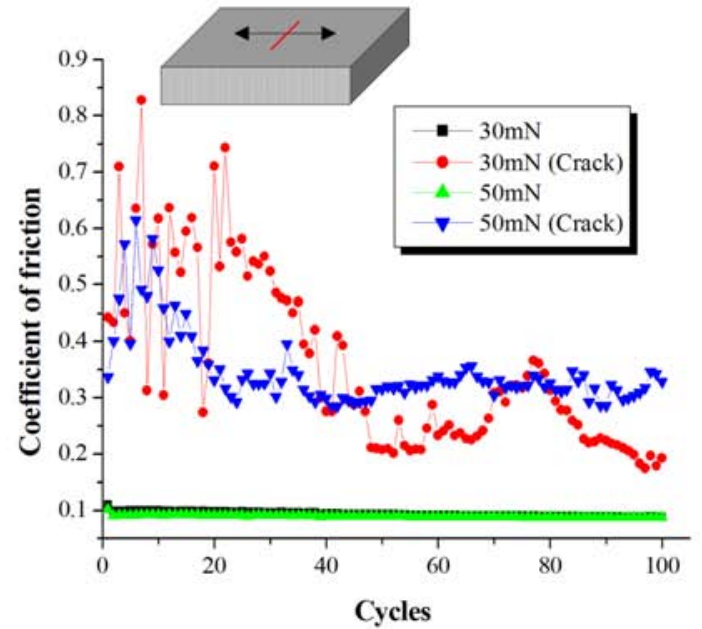

Figure 12: Evolution of the friction coefficient in the edge-on configuration perpendicular to the sliding direction (a) in absence, and $(b)$ in presence of initial scratch
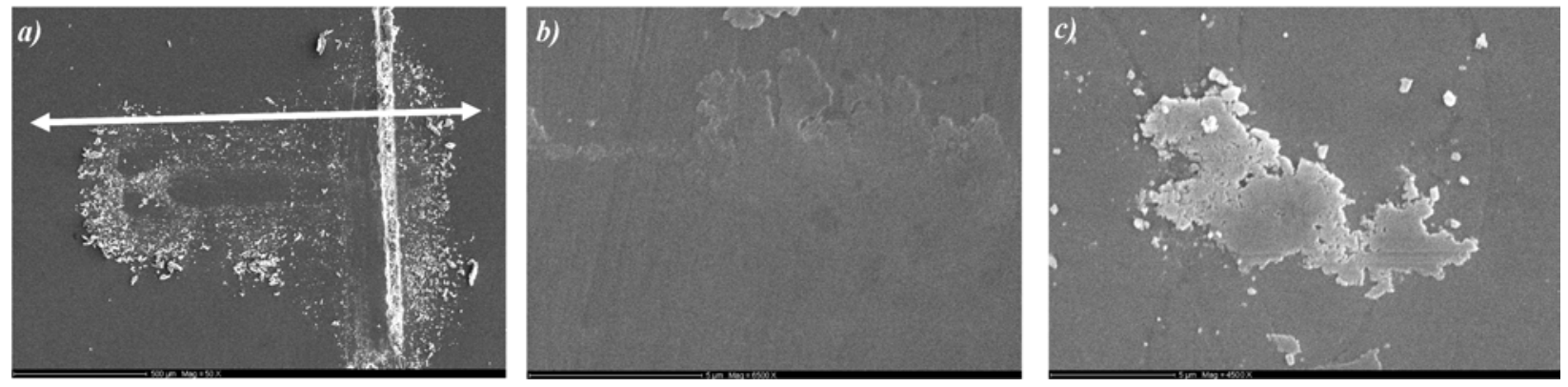

Figure 13: (a) Typical SEM views of the friction track after 100 cycles, in presence of initial scratch; (b) enlargement on the friction track (c) typical view of the discontinuous tribolayer (bar is $500 \mu \mathrm{m}, 5 \mu \mathrm{m}$ and $5 \mu \mathrm{m}$, respectively) 
Hence, the main wear mechanism does not change from low to high level regime: it involves the "intracrystalline" matrix only, as also reported for the face-on low regime configuration (§ 3.1.2). The main difference between these configurations (see fig 10a and 14a) seems just linked: (i) to the amount of trapped wear debris, and (ii) to the type of generated tribolayers - rather heterogeneous and discontinuous here (fig 13c) instead of homogeneous and continuous in fig 10b. This difference can appear obvious by considering that the presence of a much more important number of vertical organic/mineral interfaces (fig 15) is able to change a continuous wear phenomenon (face-on) into a discontinuous one (edge-on).

So, in the edge-on high level regime (i.e in presence of initial cracks), the frictional energy is probably dissipated within the cracks themselves and not by any additional wear mechanism, as reported in the faceon high level regime ( $c f . \S 3.1 .1$ ). That is in good agreement with the low amount of wear debris observed within the contact (fig 13b). To check this assumption, tribological tests are now carried out in the edge-on configuration parallel to the direction of sliding.

\subsection{Nanotribological results in the edge-on configuration parallel to the direction of sliding}

3.3.1. Tribological behaviour on virgin polished surfaces and in presence of an initial scratch

Fig 16a shows the evolution of the coefficient of friction vs. number of cycles, for various normal loads, in the edge-on configuration parallel to the direction of sliding. Apart some instability at low load, its behaviour is similar to the previous configuration one. The frictional dissipated energy is even reduced by a factor 1.5 (fig 16b). Besides, the difference between the "forward" and "backward" friction coefficient is now greater than the standard deviation of the friction coefficient, while the nacre microarchitecture does not even change as a function of the direction of sliding. That means that something, which is connected to the reduction of the frictional dissipated energy, could have changed in the main wear mechanism. So, what is the frictional behaviour in presence of an initial scratch? (fig 17)

Surprisingly, the friction coefficient stays low whatever the direction of the initial scratch - perpendicular or parallel - to the direction of sliding (fig 17a and b). Besides, no debris is observed within the contact, even in presence of scratch (fig 18).

\subsection{2. in situ tribological behaviour}

Results are confirmed by the wear profile analyses whatever the orientation of the initial scratch vs. the sliding direction (fig $19 \mathrm{a}$ and b). No significant tribolayer is built-up within the contact. No wear is observed either, because the continuous drop of the wear profile corresponds in fact to a deformation of the tablets squeezed under the slider. Indeed, an irreversible deformation induced by a possible plastic deformation of the "interlaminar" matrix is also observed on the typical AFM view of the friction track after sliding (fig 19c). As shown in this topographical view, the value of the final deformation is quite similar to the one of the in situ wear profile assessed just before unloading (eg. 19b). Thus, the final elastic recovery is very low 

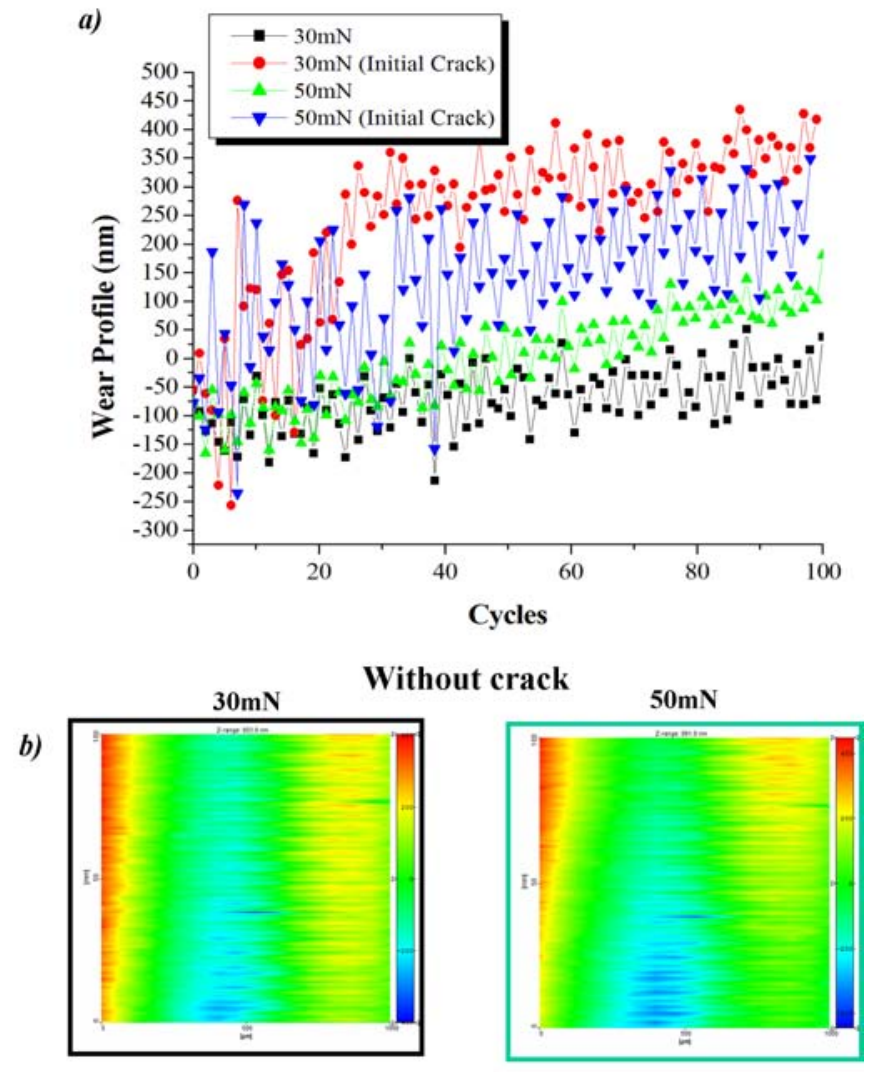

c)

With initial crack
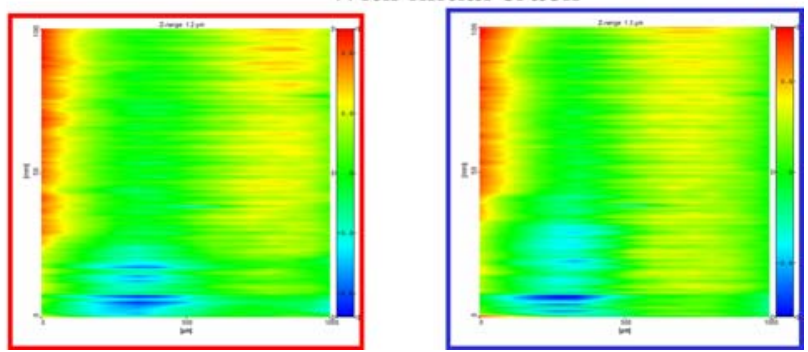

Figure 14: in situ tribological behaviour in the edge-on configuration perpendicular to the sliding direction, for two applied normal load $(30 \mathrm{mN}$ and $50 \mathrm{mN})$ : (a) various in situ wear profiles carried out in the center of the friction track, in absence and in presence of initial scratch, respectively; Corresponding wear maps (b) in absence, and (c) in presence of initial scratch 


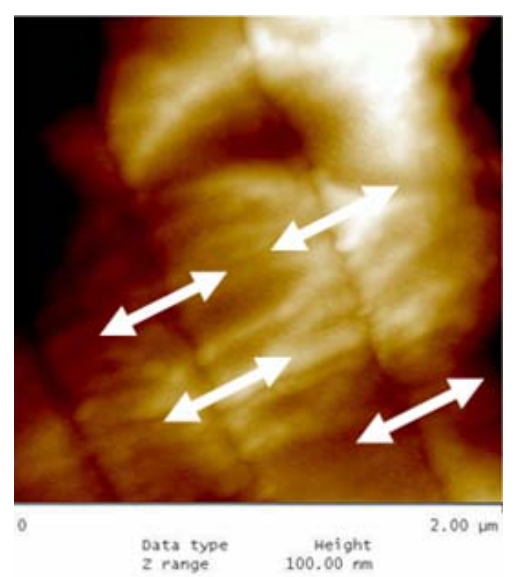

Figure 15: Effect of the vertical organic/mineral interfaces on the frictional dissipation mechanism in the edge-on configuration perpendicular to the sliding direction

a)

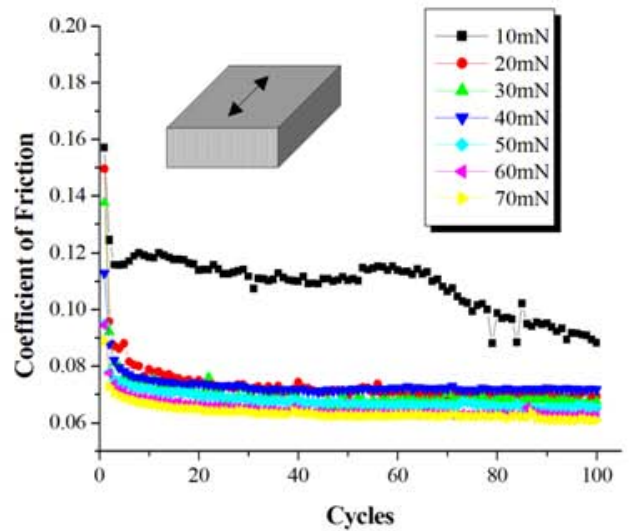

b)

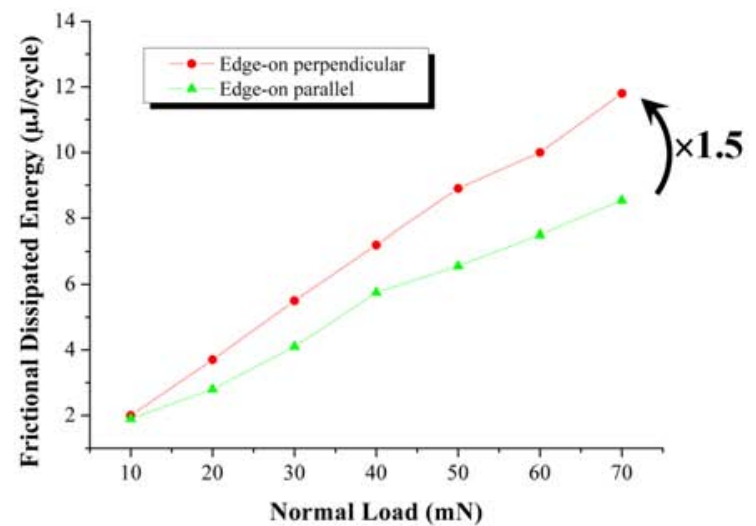

Figure 16: Frictional features in the edge-on configuration parallel to the sliding direction: (a) Evolution of the friction coefficient with the number of cycles ; (b) Evolution of the frictional dissipated energy with the applied normal load

a)

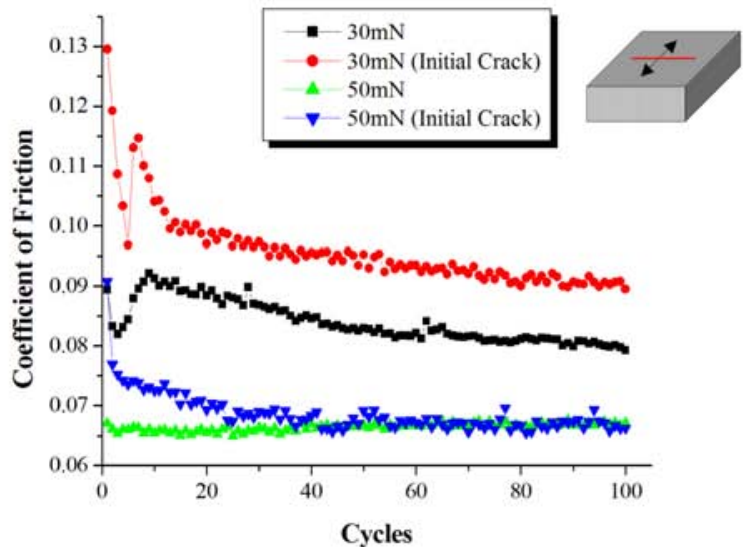

b)

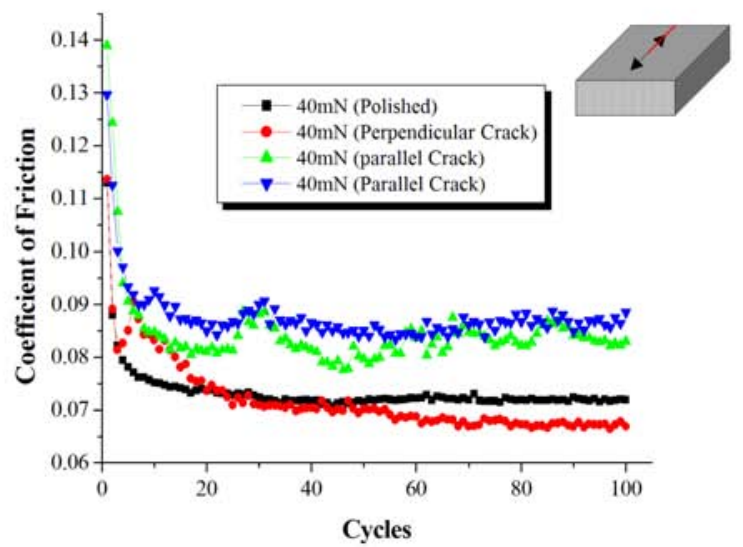

Figure 17: Influence of the presence of an initial scratch (a) perpendicular and (b) parallel to the direction of sliding on the frictional behaviour 
and quite negligible compared to the plastic deformation. Besides, since this irreversible deformation already appears at beginning of the test, one can think that the reduction of the friction dissipated energy - with respect to the previous configuration (fig 16b) - is probably connected here to the absence of any wear process. So, fracturing the organic matrices needs more energy than their deformations alone: the "intracrystalline" matrix needs only 1.5 times more energy for being fractured in contrast to the "interlaminar" one, which needs at least 4 times more. This is in-line with recent results obtained by a different approach [76]

\subsection{Discussion - Various friction-induced energy dissipation mechanisms of sheet nacre}

In the face-on configuration, there are two tribological regimes. The lower regime is obtained on a polished surface. The transition to the upper regime occurs if the track crosses scratches or cracks with a critical depth higher than the thickness of a tablet (more than $500 \mathrm{~nm}$ ). Thus, any significant change in the roughness can involve this transition, which is clearly controlled by the shear resistance of the "interlaminar" matrix (polysaccharides in-between the tablets), as reported in the fig 11c.

- The low level regime (fig 20a) occurs in abscence of any critical cracks or scratches. The friction coefficient and the wear rate are low because only one layer of tablets is involved during the tribological process. The wear mechanism involves (i) the deformation of the tablet and (ii) the fracturing of the "intracrystalline" organic matrix as a continuous shear process. Besides, the difference between the friction "forward" and "backward" is significant vs. the standard deviation of the friction coefficient. So, an effect of the sliding direction is then observed due to the microarchitecture of nacre. Consequently, the low frictional energy is dissipated by fracturing the "intracrystalline" organic matrix after deformation of the tablets. The tribolayer is rather continuous and consists of nanograins torn away from the surface.

- The high level regime (fig 20b) occurs in presence of critical cracks. The friction coefficient and the wear rate are quite high. The wear mechanism involves the fracturing of the both organic matrices as a continuous process. Nevertheless, the high frictional energy is mainly dissipated by fracturing the "interlaminar" matrix, 4 times stronger than the "intracrystalline" one. Consequently, the effect of the direction of sliding ("back" and "forward") is not relevant here, because the difference is greatly lower than the standard deviation of the friction coefficient. The tribolayer is constituted by very huge debris and pieces of fractured tablets.

In the edge-on configuration, there are two tribological behaviours which depend on the orientation of the tablets with respect to the direction of sliding:

- In edge-on configuration perpendicular to the direction of sliding (fig 20c), the friction coefficient is very sensitive to the presence of scratches or cracks. So, this way, roughness controls two antagonistic 
a)

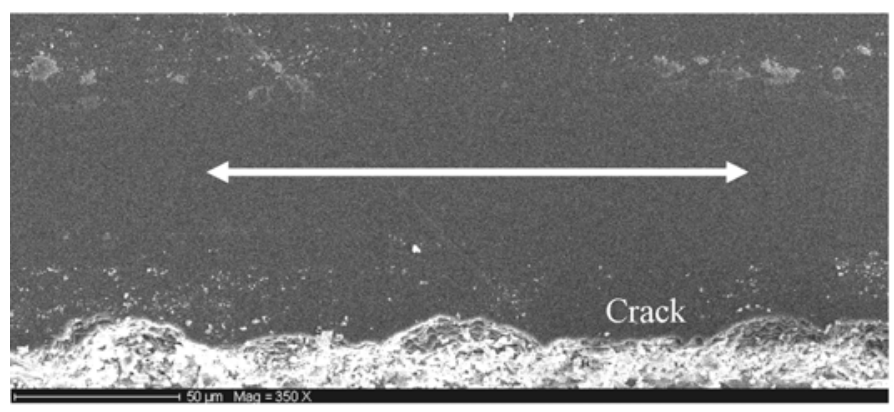

b)

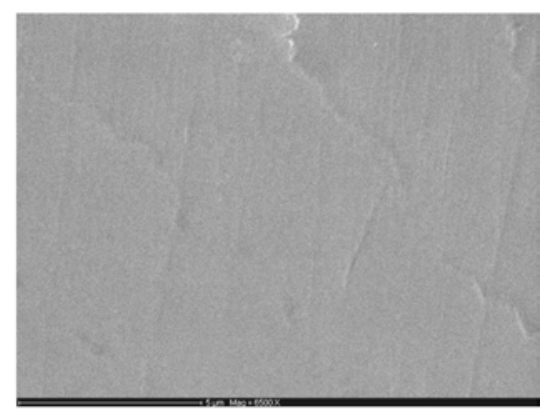

Figure 18: Typical views in the edge-on configuration parallel to the sliding direction: (a) friction track after sliding and, (b) enlargement: No tribolayer is really observed in this configuration (bar is $50 \mu \mathrm{m}$ and $5 \mu \mathrm{m}$, respectively)

a)

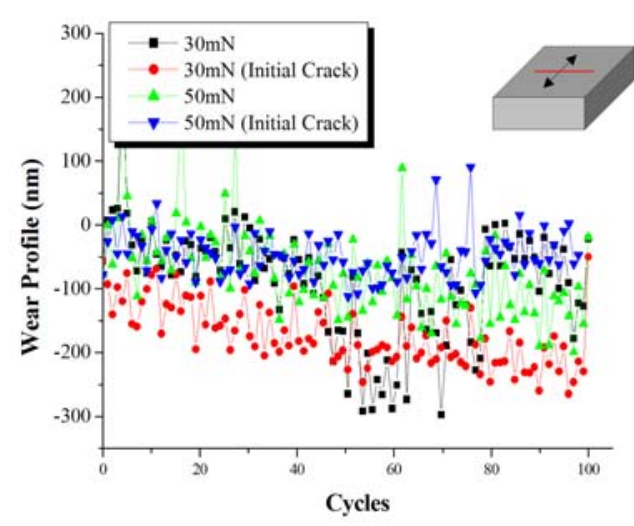

b)

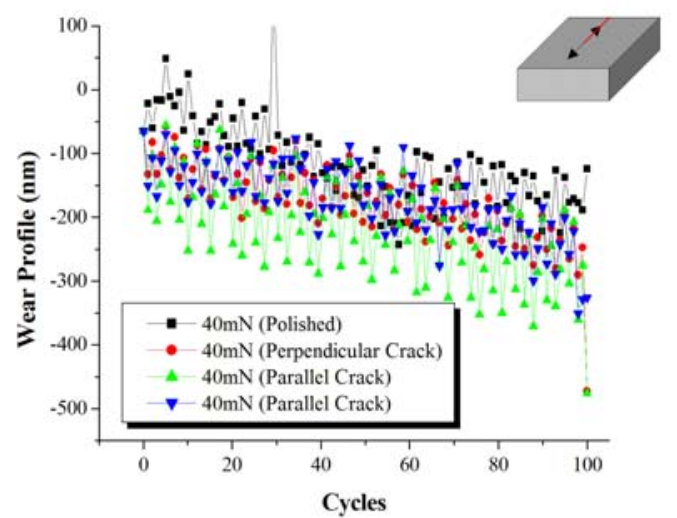

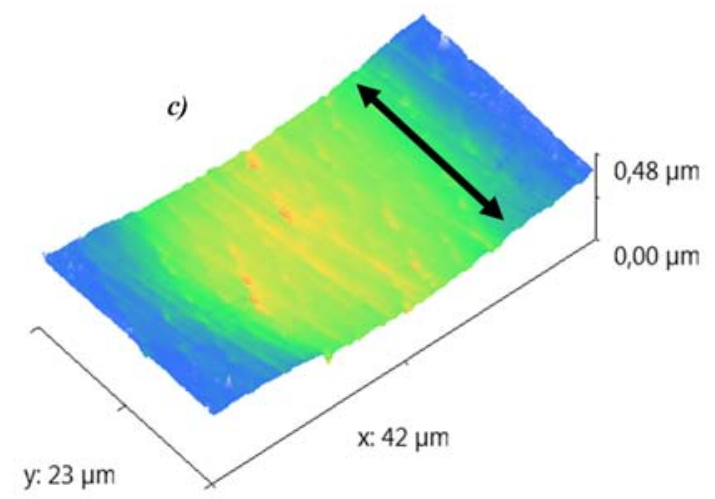

Figure 19: in situ wear profile assessments carried out in the edge-on parallel direction in absence and in presence of initial scratch (a) perpendicular and (b) parallel to the sliding direction, respectively; (c) Typical AFM view of the friction track after sliding 
friction regimes. In contrast, wear - as a discontinuous process due to the orientation of the tablets - is always low: the tablets are never really damaged, even in presence of critical cracks, as schematized in fig 20c. The frictional energy is probably dissipated within the two matrices during the low level regime, and within the cracks themselves (without additional wear process) during the high level one. Besides, all the low levels are similar whatever the orientation of the tablets (face-on or edge-on). As suggested by the arrows in fig 20c, frictional energy is mainly dissipated at the location of the vertical interfaces between the tablets and the "interlamellar" organic matrix, as successive tension/compression events (cf. fig 15).

- In the edge-on configuration parallel to the direction of sliding (fig 20d), the friction coefficient and the wear rate are extremely low, even in presence of scratches or cracks - parallel or perpendicular to the direction of sliding. However, a residual strain is clearly observed after the tests. The frictional energy is here dissipated by plastic deformation of the matrices instead of their fracturing. The difference in dissipation - 1.5 times greater when the tablets are perpendicular (fig 16) - can be explained by the absence of a real damage process.

\section{Conclusion}

Micro/nanotribological behaviour of sheet nacre, displaying various configurations, have been studied by varying the orientation of the tablets $v s$. the sliding direction. Results reveal various dissipative mechanisms controlled by the matrices orientation, which is able to involve a multiscale wear process or not. Thus, in order of importance,

- the plastic deformation of the "interlaminar" organic matrix - as observed in the edge-on orientation parallel to the sliding direction - is the less dissipative way. Dissipation is made by friction on the edge-on tablets only, after an irreversible deformation of the matrices ;

- the fracturing of the "intracrystalline" matrix - as observed both (i) in the face-on low level regime and (ii) in the edge-on orientation perpendicular to the sliding direction - which involves a much more dissipative energy due the generation of nanosized wear debris ;

- and, the fracturing of the "interlaminar" organic matrix, which is the greatest dissipative way. It involves the generation of huge wear debris, and is mainly observed in the face-on configuration when the roughness reaches a critical value. 


\section{Acknowledgements}

This work was supported by grants from the Agence Nationale de la Recherche Française under the awards NanoBioCarbonate ANR 10 INTB 90901 Organic mediation on nanostructured biomaterials, biomimetic example of otoliths and freshwater pearls.

\section{References}

[1] X. D. Li, W. C. Chang, Y. J. Chao, R. Wang, M. Chang, Nanoscale structure and mechanical characterization of a natural nanocomposite material: the shell of red abalone, Nano Letters 4 (4) (2004) $613-617$.

[2] X. D. Li, Z.-H. Xu, R. Wang, In situ observation of nanograin rotation and deformation in nacre, Nano Letters 6 (10) (2006) 2301-2304.

[3] M. Rousseau, E. Lopez, P. Stempflé, M. Brendlé, L. Francke, A. Guette, R. Naslain, X. Bourrat, Multiscale structure of sheet nacre, Biomaterials 26 (2005) 6254-6262.

[4] M. Rousseau, X. Bourrat, P. Stempflé, M. Brendlé, E. Lopez, Multi-scale structure of the pinctada mother of pearl: Demonstration of a continuous and oriented organic framework in a natural ceramic, Key Engineering Materials 284-286 (2005) 705-708.

[5] S. Weiner, W. Traub, Macromolecules in mollusc shells and their functions in biomineralization, Phil. Trans. R. Soc. Lond. B 304 (1984) 425-434.

[6] L. Bédouet, M. Schuller, F. Marin, C. Milet, E. Lopez, M. Giraud, Soluble proteins of the nacre of the giant oyster pinctada maxima and of the abalone haliotis tuberculata: extraction and partial analysis of nacre proteins, Comparative Biochemistry and Physiology B 128 (2001) 389-400.

[7] L. Pereira-Mouriès, M.-J. Almeida, C. Ribeiro, J. Peduzzi, M. Barthélemy, C. Milet, E. Lopez, Soluble silk-like organic matrix in the nacreous layer of the bivalve pinctada maxima, Euro. J. Biochem 269 (2002) 4994-5003.

[8] M. Rousseau, L. Pereira-Mouriès, M.-J. Almeida, C. Milet, E. Lopez, The water-soluble matrix fraction from the nacre of pinctada maxima produces earlier mineralization of mc3t3-e1 mouse pre-osteoblasts, Comparative Biochemistry and Physiology B 135 (2003) 1-7.

[9] M. Rousseau, A. Meibom, M. Gèze, X. Bourrat, M. Angellier, E. Lopez, Dynamics of sheet nacre formation in bivalves, Journal of Structural Biology 165 (2009) 190-195. 
[10] Y. Levi-Kalisman, G. Falini, L. Addadi, S. Weiner, Structure of the nacreous organic matrix of a bivalve mollusk shell examined in the hydrated state using cryo-tem, J Structural Bio 135 (2001) 8-17.

[11] F. Song, X. Zhang, Y. Bai, Microstructure and characteristics in the organic matrix layers of nacre, J. Mater. Res. 17 (7) (2002) 1567-1570.

[12] G. Falini, S. Weiner, L. Addadi, Chitin-silk fibroin interactions: relevance to calcium carbonate formation in invertebrates, Calcif Tissue Int 72 (2003) 548-554.

[13] F. Song, A. Soh, Y. Bai, Structural and mechanical properties of the organic matrix layers of nacre, Biomaterials 24 (2003) 3623-3631.

[14] X. Bourrat, L. Qiao, Q. Feng, M. Angellier, A. Disseaux, J.-M. Beny, V. Barbin, P. Stempflé, M. Rousseau, E. Lopez, Origin of growth defects in pearl, Materials Characterization 72 (2012) 94103.

[15] J. Currey, Mechanical properties of mother-of-pearl in tension, Proc. R Soc London B 196 (1977) 443463.

[16] A. Jackson, J. Vincent, R. Turner, Comparison of nacre with other ceramic composites, J. Mater. Sci. 25 (1990) 3173-3178.

[17] K. Okumura, P.-G. de Gennes, Why is nacre strong? elastic theory and fracture mechanics for biocomposites with stratified structures, Eur. Phys. J. E 4 (2001) 121-127.

[18] K. Okumura, Why is nacre strong? ii. remaining mechanical weakness for cracks propagating along sheets, Eur. Phys. J. E 7 (2002) 303-310.

[19] B. Ji, H. Gao, Mechanical properties of nanostructure of biological materials, Journal of the Mechanics and Physics of Solids 52 (2004) 1963-1990.

[20] M. Meyers, P.-Y. Chen, A.-M. Lin, Y. Seki, Biological materials: Structure and mechanical properties, Progress in Materials Science 53 (2008) 1-206.

[21] B. Bruet, H. Qi, M. Boyce, et al., Nanoscale morphology and indentation of individual nacre tablets from the gastropod mollusc trochus niloticus, Journal of Materials Research 20 (9) (2005) 2400-2419.

[22] P. Westbroek, F. Marin, A marriage of bone and nacre, Nature 392 (1998) 861-862.

[23] G. Atlan, O. Delattre, S. Berland, A. LeFaou, G. Nabias, D. Cot, E. Lopez, Interface between bone and nacre implants in sheep, Biomaterials 20 (1999) 1017-1022. 
[24] Y. Kim, J. Kim, Y. Kim, J.-Y. Rho, Effect of organic matrix proteins on the interfacial structure at the bone biocompatible nacre interface in vivo, Biomaterials 23 (2002) 2089-2096.

[25] H. Liao, H. Mutvei, L. Hammarström, T. Wurtz, J. Li, Tissue responses to nacreous implants in rat femur: an in situ hybridation and histochemical study, Biomaterials 23 (2002) 2693-2701.

[26] E. Lopez, S. Berland, C. Camprasse, G. Camprasse, C. Silve, Demonstration of the capacity of nacre to induce bone formation by human osteoblasts maintained in vitro, Tissue Cell 24 (1992) 667-679.

[27] S. Berland, O. Delattre, S. Borzeix, Y. Catonné, E. Lopez, Nacre/bone interface changes in durable nacre endosseous implants in sheep, Biomaterials 26 (2005) 2767-2773.

[28] C. Silve, E. Lopez, B. Vidal, D. Smith, G. Camprasse, C. Camprasse, G. Couly, Nacre initiates biomineralization by human osteoblasts maintained in vitro, Calcif Tissue Int 51 (5) (1992) 363-369.

[29] A. Heuer, D. Fink, V. Laraia, J. Arias, P. Calvert, K. Kendall, Innovative materials processing strategies: a biomimetic approach, Science 255 (1992) 1098-1105.

[30] S. Weiner, L. Addadi, Design strategies in mineralized biological materials, J Mater Chem 7 (5) (1997) 689-702.

[31] C. Wang, Y. Huang, Q. Zan, H. Guo, S. Cai, Biomimetic structure design - a possible approach to change the brittleness of ceramics in nature, Materials Science and Engineering C 11 (2000) 9-11.

[32] J. Carlson, S. Ghaey, S. Moran, C. Tran, D. Kaplan, Biological materials in engineering mechanisms, in: Y. E. Bar-Cohen (Ed.), Biomimetics, Biologically Inspired Technologies, CRC Taylor \& Francis, Boca Raton, FL, 2006, pp. 365-379.

[33] P. Fratzl, Biomimetic materials research: what can we really learn from nature's structural materials?, J. R. Soc. Interface 4 (2007) 637-642.

[34] E. Munch, M. Launey, D. Alsem, E. Saiz, A. Tomsia, R. Ritchie, Tough, bio-inspired hybrid materials, Science 322 (2008) 516-520.

[35] B. Bhushan, Biomimetics: Lessons from nature - an overview, Phil Trans. R. Soc. A 367 (2009) 14451486.

[36] P. Stempflé, M. Brendlé, Tribological behaviour of nacre - influence of the environment on the elementary wear processes, Tribology International 39 (2006) 1485-1496. 
[37] P. Stempflé, O. Pantalé, R. Kouitat Njiwa, M. Rousseau, E. Lopez, X. Bourrat, Friction-induced sheet nacre fracture: effects of nano-shocks on cracks location, Int. J. Nanotechnol. 4 (6) (2007) 712-729.

[38] P. Stempflé, T. Djilali, R. Kouitat Njiwa, M. Rousseau, E. Lopez, X. Bourrat, Thermal-induced wear mechanisms of sheet nacre in dry friction, Tribology Letters 35 (2009) 97-104.

[39] P. Stempflé, O. Pantalé, T. Djilali, R. Kouitat Njiwa, X. Bourrat, Evaluation of the real contact area in three-body dry friction by micro-thermal analysis, Tribology International 43 (2010) 1794-1805.

[40] P. Stempflé, T. Djilali, R. Kouitat Njiwa, M. Rousseau, E. Lopez, X. Bourrat, Assessment of the thermalinduced wear mechanisms of sheet nacre by using scanning thermal microscopy, in: Proceedings of the 3rd International Conference NANOTECHNOLOGY - Viennano'09, March 18-20, 2009; Vienna, Austria, 2009, pp. 409-414.

[41] X. Bourrat, L. Francke, E. Lopez, M. Rousseau, P. Stempflé, M. Angellier, P. Albéric, Nacre biocrystal thermal behaviour, CrystEngComm 9 (2007) 1205-1208.

[42] R. Wang, H. Wen, F. Cui, H. Zhang, H. Li, Observations of damage morphologies in nacre during deformation and fracture, J. Mater. Sci. 30 (1995) 2299-2304.

[43] A. Evans, Z. Suo, R. Wang, I. Aksay, M. He, J. Hutchinson, Model for the robust mechanical behaviour of nacre, J. Mater. Res. 16 (9) (2001) 2475-2484.

[44] R. Wang, Z. Suo, A. Evans, N. Yao, I. Aksay, Deformation mechanisms in nacre, J. Mater. Res. 16 (9) (2001) 2485-2493.

[45] K. Okumura, Fracture strength of biomimetic composites: scaling views of nacre, J. Phys.: Condens. Matter 17 (2005) S2879-S2884.

[46] T. Sumitomo, H. Kakisawa, Y. Owaki, Y. Kagawa, Transmission electron microscopy observation of nanoscale deformation structures in nacre, J. Mater. Res. 23 (12) (2008) 3213-3221.

[47] M. Meyers, A.-M. Lin, P.-Y. Chen, J. Muyco, Mechanical strength of abalone nacre: Role of the soft organic layer, Journal of the Mechanical behavior of biomedical materials 1 (2008) 76-85.

[48] A. Jackson, J. Vincent, D. Briggs, R. Crick, S. Davies, M. Hearn, R. Turner, Application of surface analytical techniques to the study of fracture surfaces of mother-of-pearl, J. Mater. Sci. Letters 5 (1986) 975-978.

[49] S. Kotha, Y. Li, N. Guzelsu, Micromechanical model of nacre tested in tension, J. Mater. Sci. 36 (2001) 2001-2007. 
[50] N. Neves, J. Mano, Structure/mechanical behavior relationships in crossed-lamellar sea shells, Materials Science and Engineering C 25 (2005) 113-118.

[51] P. Nukala, S. Simunovic, A continuous damage random thresholds model for simulating the fracture behavior of nacre, Biomaterials 26 (2005) 6087-6098.

[52] M. Cortie, K. McBean, M. Elcombe, Fracture mechanics of mollusc shells, Physica B 385-386 (2006) $545-547$.

[53] F. Barthelat, H. Tang, P. Zavattieri, C.-M. Li, H. Espinosa, On the mechanics of mother-of-pearl: A key feature in the material hierarchical structure, Journal of the Mechanics and Physics of Solids 55 (2007) 306-337.

[54] K. Okumura, Enhanced energy of parallel fractures in nacre-like composite materials, Europhys. Lett. 63 (5) (2003) 701-707.

[55] J. Vincent, Structural Biomaterials, revised edition Edition, Princeton University Press, 1990.

[56] H. Qi, B. Bruet, J. Palmer, C. Ortiz, M. Boyce, Micromechanics and macromechanics of the tensile deformation of nacre, in: G. Holzapfel, R. (eds) Ogden (Eds.), Mechanics of Biological Tissue, Springer Verlag Berlin Heidelberg, 2006, p. 189.

[57] R. Menig, M. Meyers, M. Meyers, K. Vecchio, Quasi-static and dynamic mechanical response of haliotis rufescens (abalone) shells, Acta mater. 48 (2000) 2383-2398.

[58] V. Laraia, A. Heuer, The microindentation behavior of several mollusk shells, Mat Res Soc Symp Proc 174 (1990) 125-131.

[59] L. Ge, N. Kim, G. R. Bourne, W. G. Sawyer, Material property identification and sensitivity analysis using micro-indentation, Journal of Tribology 131 (2009) 031402-1 7.

[60] P. Stempflé, O. Pantalé, R. Kouitat Njiwa, M. Rousseau, E. Lopez, X. Bourrat, Nanoindentation \& tribological tests - suitable tools for modelling the nanostructure of sheet nacre, in: W. Bartz, F. Franek (Eds.), Proceedings of the 2rd International Conference MICRO-NANOTECHNOLOGY - Viennano'07, March 2007; Vienna, Austria, 2007, pp. 153-159.

[61] B. Mohanty, K. Katti, D. Katti, Experimental investigation of nanomechanics of the mineral-protein interface in nacre, Mechanics Research Communications 35 (2008) 17-23.

[62] P. Stempflé, O. Pantalé, M. Rousseau, E. Lopez, X. Bourrat, Mechanical properties of the elemental nanocomponents of nacre structure, Materials Science and Engineering C 30 (2010) 715-721. 
[63] P. Stempflé, X. Bourrat, R. Kouitat, M. Rousseau, E. Lopez, Mechanical properties of sheet nacre porous intercrystalline organic matrix, to be published.

[64] M. Scherge, S. Gorb, Microtribology of biological materials, Tribology Letters 8 (2000) 1-7.

[65] M. Scherge, S. Gorb, Biological Micro- Nano-tribology, Springer Verlag Berlin Heidelberg New York, 2001.

[66] P. Stempflé, J. Takadoum, Multi-asperity nanotribological behavior of single-crystal silicon: Crystallography-induced anisotropy in friction and wear, Tribology International 48 (2012) 35-43.

[67] D. Sud, D. Doumenc, E. Lopez, C. Milet, Role of water-soluble matrix fraction, extracted from the nacre of pinctada maxima, in the regulation of cell activity in abalone mantle cell culture (haliotis tuberculata), Tissue \& Cell 33 (2) (2001) 154-160.

[68] L. Addadi, S. Weiner, A pavement of pearl, Nature 389 (1997) 912-913.

[69] L. Huang, H. Li, The microstructure of the biomineralization bivalvia shells, Mater Res Soc Symp Proc 174 (1990) 101-108.

[70] R. Maev, Acoustic Microscopy: Fundamentals and Applications, Wiley-VCH Verlag, 2008.

[71] Z.-H. Xu, Y. Yang, Z. Huang, X. Li, Elastic modulus of biopolymer matrix in nacre measured using coupled atomic force microscopy bending and inverse finite element techniques, Materials Science and Engineering C 31 (2011) 1852-1856.

[72] P. Stempflé, J. Takadoum, R. Kouitat Njiwa, An accurate in-situ wear assessment in micro/nanotribology, in: W. Bartz, F. Franek (Eds.), Proceedings of the 3rd European Conference on Tribology, June 7-9, 2011; Vienna Austria, 2011.

[73] I. Hill, W. G. Sawyer, Energy, adhesion, and the elastic foundation, Tribol Lett 37 ((2010)) 453-461.

[74] P. Stempflé, F. Pollet, L. Carpentier, Influence of intergranualr metallic nanoparticles on the fretting wear mechanisms of fe-cr-al2o3 nanocomposites rubbing on ti-6al-4v, Tribology International 41 (2008) 1009-1019.

[75] P. Stempflé, J. von Stebut, Nano-mechanical behaviour of the 3rd body generated in dry friction feedback effect of the 3rd body and influence of the surrounding environment on the tribology of graphite, Wear 260 (2006) 601-614.

[76] J. Bezares, R. Asaro, M. Hawley, Macromolecular structure of the organic framework of nacre in haliotis rufescens: Implications for mechanical response, Journal of Structural Biology 170 (2010) 484-500. 
a)

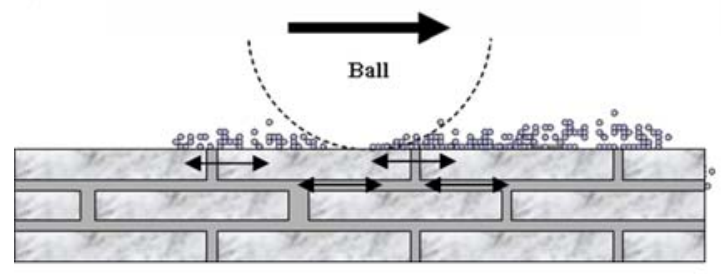

c)

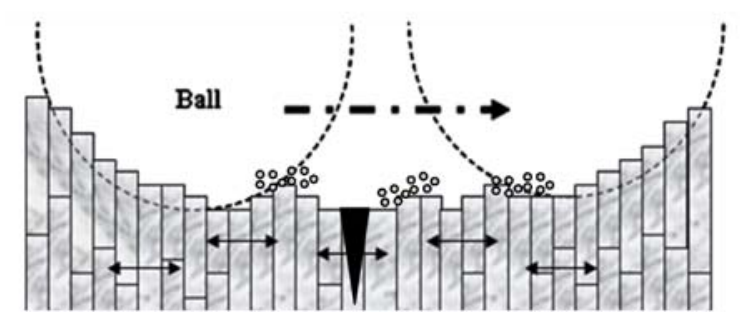

b)

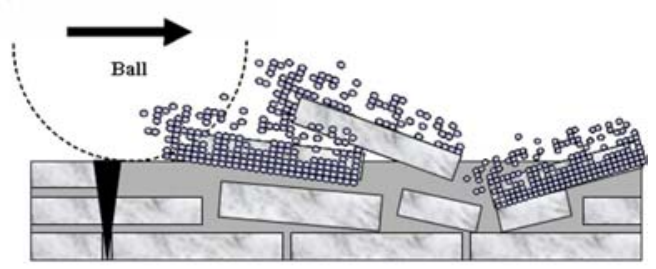

d)

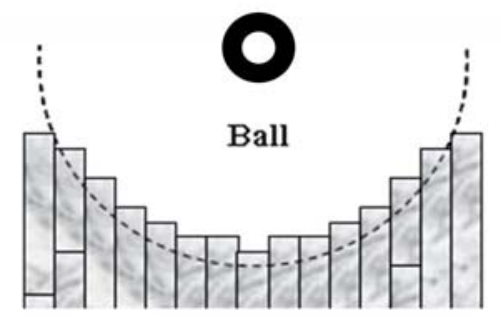

Figure 20: Various friction-induced energy dissipation ways of sheet nacre as a function of its orientation: (a) face-on low level regime; (b) face-on high level regime ; edge-on perpendicular (c) and parallel (d) to the sliding direction 